\title{
SIMULATION AND EXPERIMENTAL RESULTS FOR THE CLOSED LOOP CONTROLLED DC TO DC FORWARD CONVERTER
}

\author{
A. Palamalai VIJAYAKUMAR ${ }^{*}$, Ramakrishnan DEVI ${ }^{* *}$ \\ *Department of Electrical and Electronics, Faculty of Electrical Engineering, HK Electronics Research Center and Project \\ Consultancy, Pallikaranai, Chennai, India, Tel.: +91944 410 9915, E-mail: apvkumar75@gmail.com \\ ${ }^{* *}$ Department of Computer Science, Faculty of Computer Science and Engineering, Panimalar Engineering College, Nazarethpet, \\ Poonamallee, Chennai, Tamil Nadu, India, E-mail: deviramakrishnan83@gmail.com
}

\begin{abstract}
A Closed loop controlled DC to DC forward converter is a requisite for the server SMPS system. High efficiency, Isolation, Steady state voltage, Transient response, High switching frequency, reduced noises and range of steady state are all necessary requirements for the forward converter. In this paper, a $40 \mathrm{~V}$ forward converter for charging the battery of server SMPS is proposed. The proposed converter consists of a NPC-ARS circuit for soft switching on the primary side and an isolation transformer and a rectifier structure on the secondary side. With this modified NPC-ARS circuit topology, soft switching occurs during conversion and reduces the switching loss in this system. This paper proposed the simulation of closed loop controlled circuit, for the forward converter with RCD snubber, double forward converter and the Modified forward converter are analyzed and discussed in this paper. From comparison of performance in the closed loop model, a suitable converter is proposed for the sever SMPS system. The proposed circuit achieves steady state voltage, when the disturbance occurs. A $40 \mathrm{~V}$ proposed circuit is designed as experimental model to verify and compare the simulation and experimental results. This paper proposed the simulation and experimental results of the forward converter.
\end{abstract}

Keywords: transient response, steady state and its range, soft switching, voltage stress, peak over shoot, Zero voltage switching and ZCS

\section{INTRODUCTION}

In recent years, power semiconductor devices used by the SMPS systems have achieved high performances and with high power. Fig. 1 shows the circuit diagram of SMPS system. During turn ON and OFF the switching losses and stress occur in the power semiconductor devices used in the SMPS system. The voltage ripple during conversion and the harmonics oscillations occur in the non-linear loads. In the high frequency switching sub harmonics occur. Large signal transients and radio frequency interference (RFI) have been closed up. The special committee like CISPR and the electro-technical committee like (IEC), which aim to control the harmonics and ripple by the Electro Magnetic Compliance (EMC) limitation. To reduce the harmonics in the SMPS system it can be designed with large input filter, keeping the above given constraint in mind. The metal shield to attenuate the electromagnetic interference or radio frequency noises should be provided. The tremendous improvement of technology in the power semiconductor device is such that the size of the components has been reduced in the SMPS system, when the switching frequency is increased. When

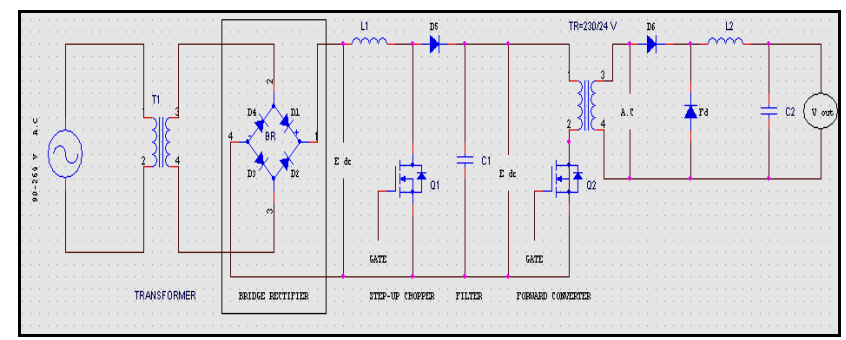

Fig. 1 Circuit diagram of a SMPS system it is operated at high frequency, the switching losses have been increased, but the inductor ' $L$ ' and size of the transformer have been reduced while the size of cooling fan could be large.

\section{A BRIEF LITERATURE REVIEW}

The new methodology is used to overcome the drawbacks and to improve the system for the society needs. The proposed converter provides higher efficiency than the NIBB converter is presented [1]. An appropriate topology of a ZVS based Phase Shifted full -bridge DCDC converter is selected based on advantages of reduced switching losses and stresses with fixed switching frequency. A feed forward voltage mode control is utilized which is easier to design and analyze with good noise margin and stable modulation process and improved line regulation are given [2]. This study presents the analysis and design of a novel technique that improves the efficiency of the conventional forward DC-DC converter by reducing switching losses, along with a comprehensive analysis of the circuit and detailed information for designers. A $5 \mathrm{~kW}$ step-down prototype is presented [3]. The auxiliary circuit has only passive elements and thus, the control circuit is simple and is like a regular PWM DC-DC converter. The auxiliary circuit provides ZVS condition for primary switch at turn-off instances. A new soft switching forward-fly-back DC-DC converter is proposed [4]. A double-sided LCLC-compensated capacitive structure dramatically reduce the voltage stress in the capacitive power transfer (CPT) system is proposed for the electric vehicle charging applications with improved efficiency are given [5]. The method to step up the voltage gain by reducing the conduction and switching losses are presented [6]. A closed loop model is proposed 
for the critical applications and the methods to improve the quality by reducing the error are presented [7]. Due to the comparison between the converters, the simulation results of the double forward converter gives better performance is proposed [8]. Comparison between the converters with constant source and with constant load, which is used to check the maximum power transfer to the load is also presented [9]. The new step up and step down method of switching is used to reduce the stress and the comparison between the simulation and experimental results is also presented [10]. The above literature does not deal with the closed loop controlled forward converter.

The above cited papers do not deal also with the modeling of closed loop SMPS system and do not identify a converter suitable for SMPS system.

This work aims to develop, simulink models for the closed loop forward converter system and the experimental models for the modified converter by using a PIC16f84 Microcontroller.

A comparison is also done between the simulation and experimental results for the modified forward converter, which is based on the output voltage to find the circuit suitable for the SMPS system.

\section{SIMULATION RESULTS}

The SMPS system is modeled and simulated using the blocks of simulink. The open loop controlled forward converter with RCD snubber is shown in Fig. 2a). DC input voltage with step change is shown in Fig. 2b). DC output voltage with step change in output is shown in Fig. 2c). Closed loop controlled forward converter with RCD snubber is shown in Fig. 2d). DC input voltage with step change is shown in Fig. 2e). DC output voltage with step change is shown in Fig. 2f). Summary of transient response and the range of steady state are shown in Table 1. Summary of steady state error is shown in Table 2.

The open loop controlled double forward converter is shown in Fig. 3a). DC input voltage with step change is shown in Fig. 3b). DC output voltage with step change is shown in Fig. 3c). Closed loop controlled double forward converter is shown in Fig. 3d). DC input voltage with step change is shown in Fig. 3e). DC output voltage with step change is shown in Fig. 3f). Summary of transient response is given in Table 3. Summary of steady state error is given in Table 4.

The open loop controlled modified forward converter is shown in Fig. 4a). DC input voltage with step change is shown in Fig. 4b). DC output voltage with step change is shown in Fig. 4c). Closed loop controlled modified forward converter is shown in Fig. 4d). DC input voltage with step change is shown in Fig. 4e). DC output voltage with step change is shown in Fig. 4f).

Summary of transient response and the range of steady state are given in Table 5. Summary of steady state error is given in Table 6. From the waveform it can be seen that the steady state error in the output is reduced. In the modified system, it has highly reduced steady state voltage. It has the maximum peak over shoot and the output is free from oscillations. The peak over shoot is $13.9 \mathrm{~V}$.

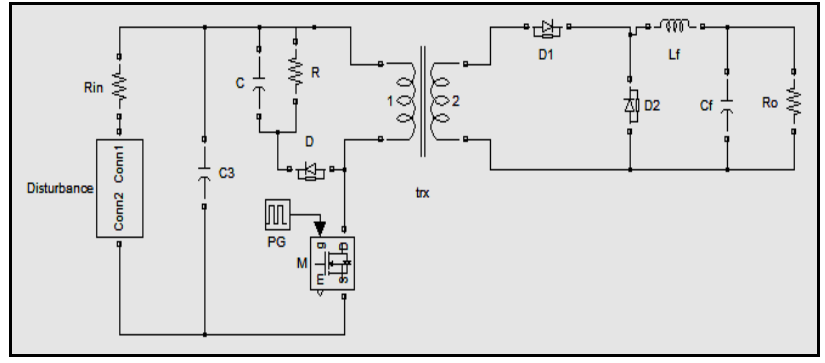

Fig. 2a) Open loop forward converter with RCD snubber

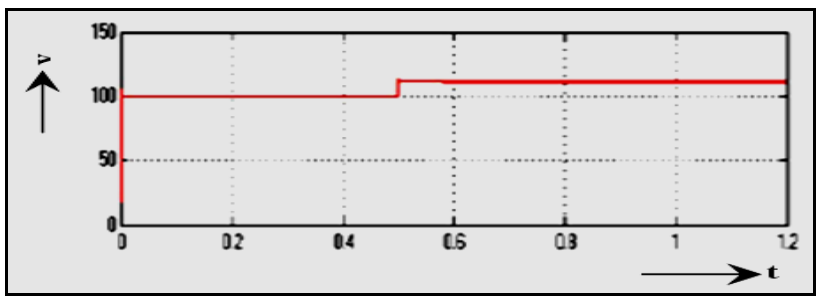

Fig. 2b) DC input voltage with disturbance

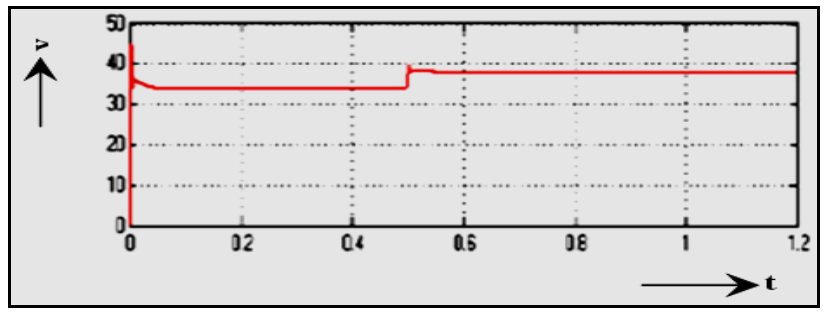

Fig. 2c) DC output voltage with disturbance

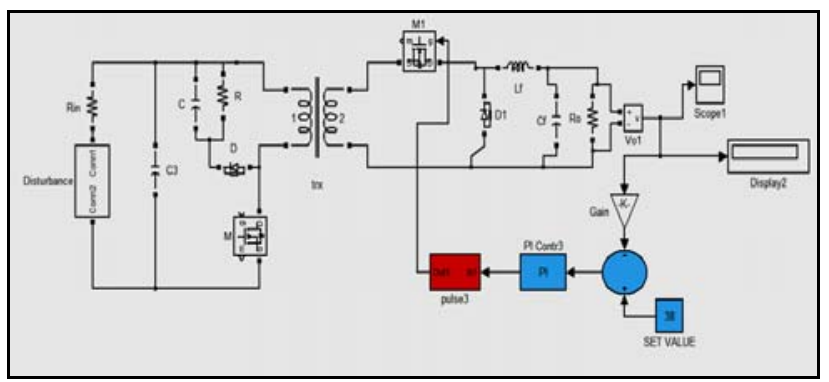

Fig. 2d) Closed loop forward converter with snubber

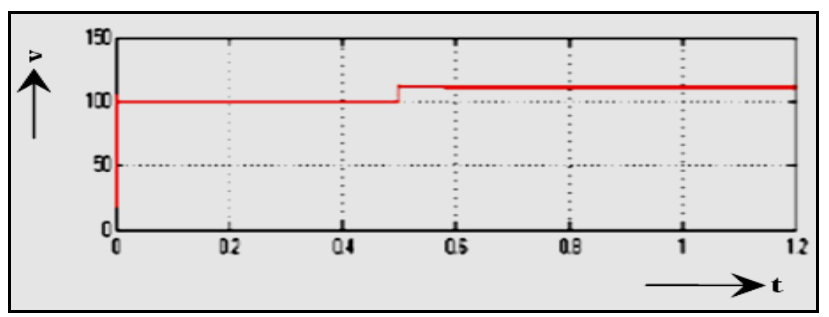

Fig. 2e) DC input voltage with disturbance

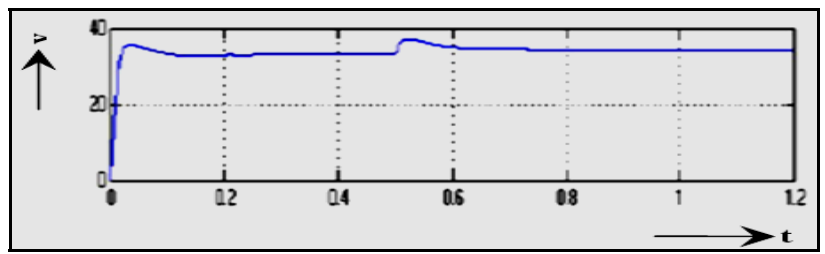

Fig. 2f) DC output voltage with steady state 
Table 1 Summary of transient response

\begin{tabular}{|c|c|c|c|}
\hline \multicolumn{4}{|c|}{ Transient Response } \\
\hline $\mathbf{t}_{\mathbf{d}}[\mathbf{m s}]$ & $\mathbf{t}_{\mathbf{r}}[\mathbf{m s}]$ & $\mathbf{t}_{\mathbf{p}}[\mathbf{m s}]$ & $\mathbf{t}_{\mathbf{s}}[\mathbf{m s}]$ \\
\hline 0.02 & 0.04 & 0.06 & 0.3 \\
\hline \multicolumn{3}{|c|}{ Transient and range of Steady state } \\
\hline Transient State [ms] & Steady State $[\mathbf{m s}]$ \\
\hline \multicolumn{3}{|c|}{$0-0.3$} & 0.3 onwards \\
\hline \multicolumn{3}{|c|}{ Peak over shoot $\mathrm{Mp}(\mathrm{A})=3.22$ volts } \\
\hline
\end{tabular}

Table 2 Summary of steady state error

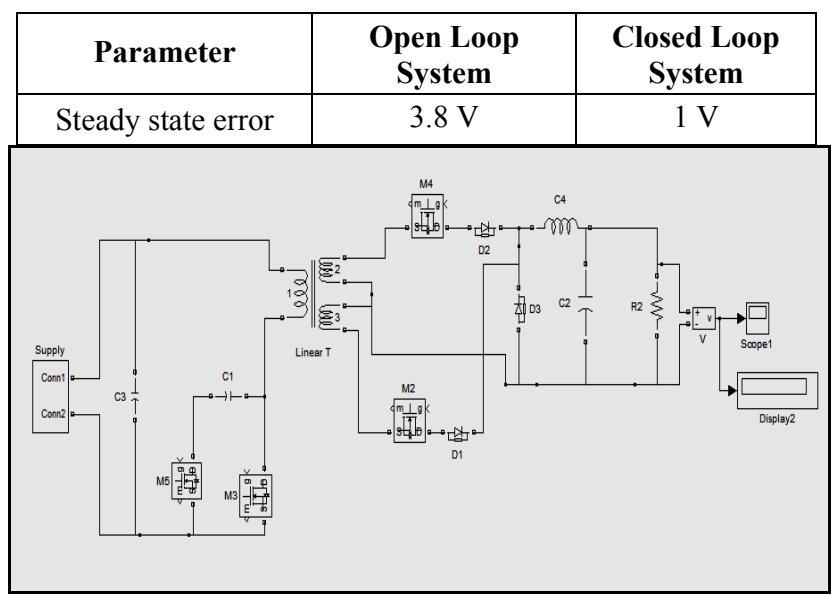

Fig. 3a) Open loop controlled double forward converter

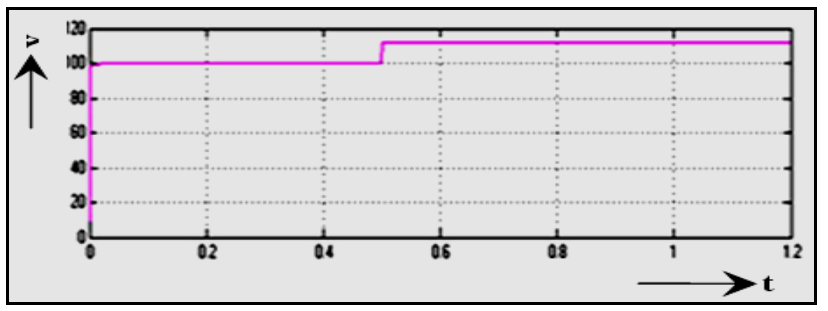

Fig. 3b) DC input voltage with disturbance

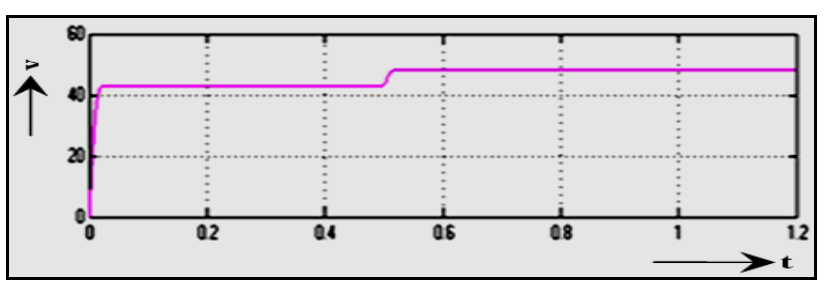

Fig. 3c) DC output voltage with disturbance

The circuit diagram shows a closed loop double forward converter with a step change at the input in Fig. $3 d)$. The output from this system is taken as feedback to get the accurate response. The change in output due to the step change in input is corrected automatically with set value, to get the desired response.

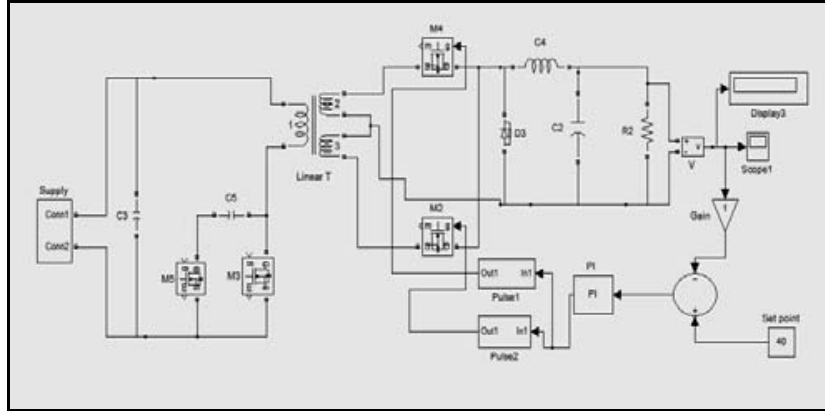

Fig. 3d) Closed loop controlled double forward converter

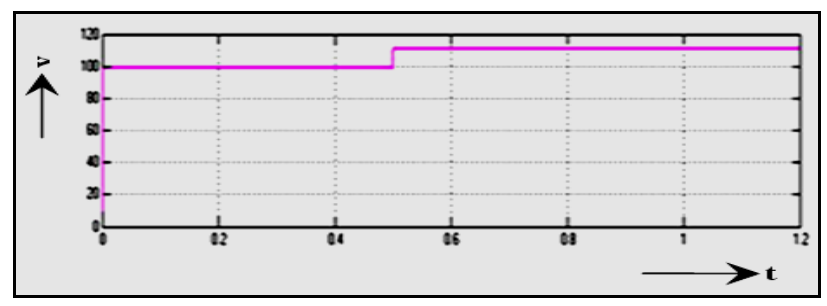

Fig. 3e) DC input voltage with disturbance

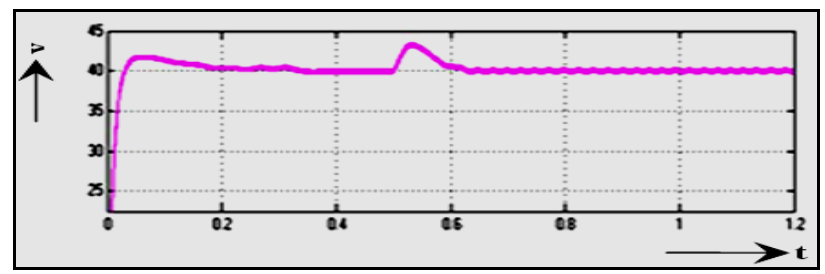

Fig. 3f) DC output voltage with steady state

Table 3 Summary of transient response

\begin{tabular}{|c|c|c|c|}
\hline \multicolumn{4}{|c|}{ Transient Response } \\
\hline $\mathbf{t}_{\mathbf{d}}[\mathbf{m s}]$ & $\mathbf{t}_{\mathbf{r}}[\mathbf{m s}]$ & $\mathbf{t}_{\mathbf{p}}[\mathrm{ms}]$ & $\mathbf{t}_{\mathbf{s}}[\mathrm{ms}]$ \\
\hline 0.01 & 0.04 & 0.1 & 0.3 \\
\hline \multicolumn{3}{|c|}{ Transient and range of Steady state } \\
\hline \multicolumn{2}{|c|}{ Transient State [ms] } & \multicolumn{2}{|c|}{ Steady State [ms] } \\
\hline \multicolumn{3}{|c|}{$0-0.3$} & onwards \\
\hline \multicolumn{3}{|c|}{ Peak over shoot $\mathrm{Mp}(\mathrm{A})=3.24$ volts } \\
\hline
\end{tabular}

Table 4 Summary of steady state error

\begin{tabular}{|c|c|c|}
\hline Parameter & $\begin{array}{c}\text { Open Loop } \\
\text { System }\end{array}$ & $\begin{array}{c}\text { Closed Loop } \\
\text { System }\end{array}$ \\
\hline Steady state error & $8 \mathrm{~V}$ & $0.5 \mathrm{~V}$ \\
\hline
\end{tabular}

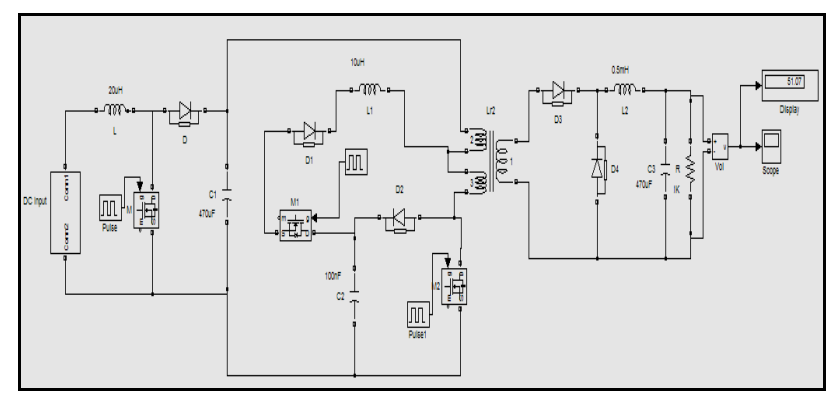

Fig. 4a) Open loop controlled modified system 


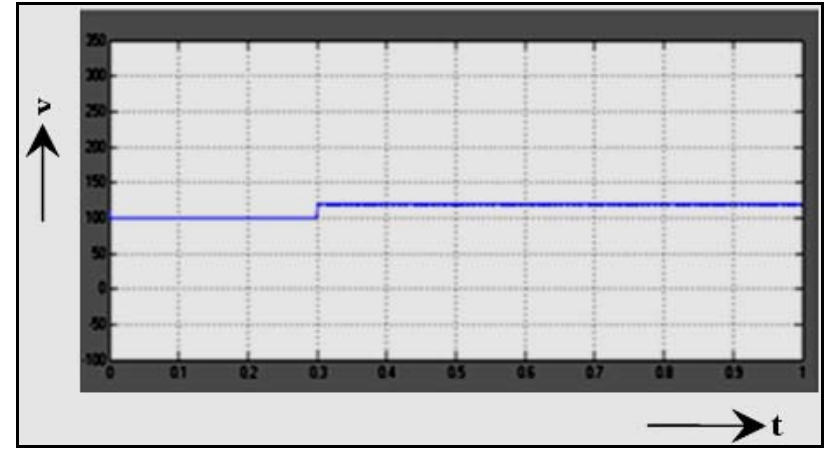

Fig. 4b) DC input voltage with disturbance

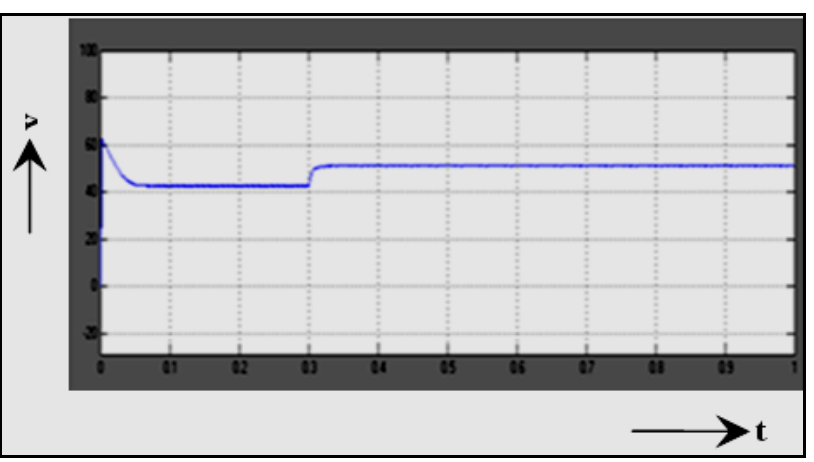

Fig. 4c) DC output voltage with steady state

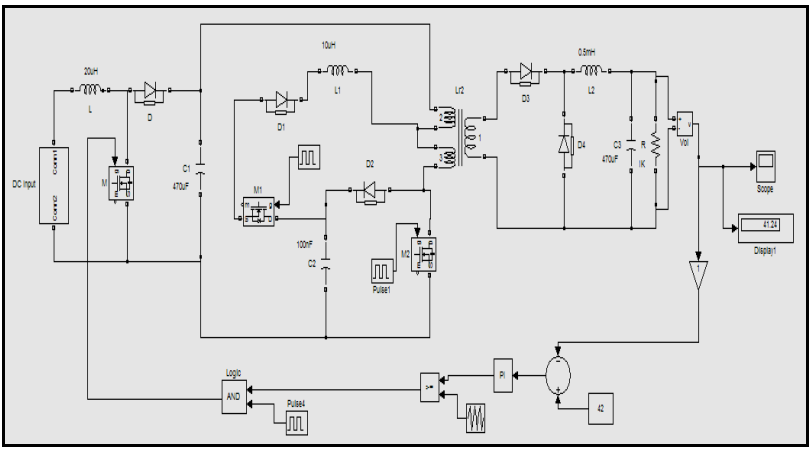

Fig. 4d) Closed loop controlled modified system

Two ideal circuit breakers are built internally to the input DC supply, which is shown in Fig. 4d). Terminal-1 with $100 \mathrm{~V}$ has an amplitude of $[0,2]$ and Terminal-2 with $12 \mathrm{~V}$ has an amplitude of $[2,0]$ in the time sequences $[0$, $0.5]$ sec. The terminal- 2 is used to induce a step change in the input of $12 \mathrm{~V}$.

Fig. 4e) DC output voltage with steady state

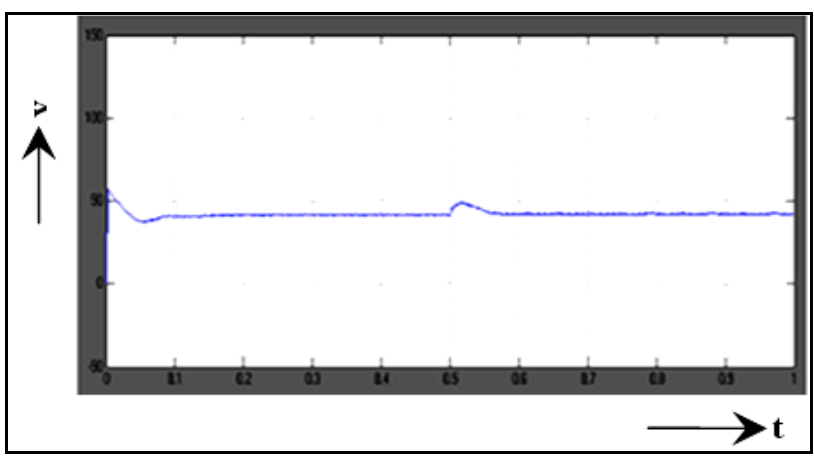

Table 5 Summary of transient response

\begin{tabular}{|l|c|c|c|}
\hline \multicolumn{4}{|c|}{ Transient Response } \\
\hline $\mathbf{t}_{\mathbf{d}}[\mathbf{m s}]$ & $\mathbf{t}_{\mathbf{r}}[\mathbf{m s}]$ & $\mathbf{t}_{\mathbf{p}}[\mathbf{m s}]$ & $\mathbf{t}_{\mathbf{s}}[\mathbf{m s}]$ \\
\hline 0.01 & 0.02 & 0.03 & 0.2 \\
\hline \multicolumn{3}{|c|}{ Transient and range of Steady state } \\
\hline \multicolumn{2}{|c|}{ Transient State [ms] } & \multicolumn{2}{|c|}{ Steady State $[\mathbf{m s}]$} \\
\hline \multicolumn{3}{|c|}{$0-0.2$ onwards } \\
\hline \multicolumn{3}{|c|}{ Peak over shoot $\mathrm{Mp}(\mathrm{A})=13.9$ volts } \\
\hline
\end{tabular}

Table 6 Summary of steady state error

\begin{tabular}{|c|c|c|}
\hline Parameter & $\begin{array}{c}\text { Open Loop } \\
\text { System }\end{array}$ & $\begin{array}{c}\text { Closed Loop } \\
\text { System }\end{array}$ \\
\hline Steady state error & $8 \mathrm{v}$ & $2 \mathrm{v}$ \\
\hline
\end{tabular}

Fig. 4c) shows the DC output voltage $41.25 \mathrm{~V}$. The step change is introduced in the input by using the circuit breakers. The closed loop system has the steady state error in the output which is reduced as shown in Fig. 4e) from the simulation results, it is confirmed that the output reaches the value of $41 \mathrm{~V}$, after $0.2 \mu$ s as steady state.

Table 7 Circuit parameters for conventional boost forward converter

\begin{tabular}{|lc|c|}
\hline Parameters & Unit & $\begin{array}{c}\text { Values and } \\
\text { Items }\end{array}$ \\
\hline Input voltage & {$[\mathrm{V}]$} & 100 \\
\hline Output voltage Vo & {$[\mathrm{V}]$} & 42 \\
\hline Switching frequency $\quad[\mathrm{kHz}]$ & 100 \\
\hline Smooth Capacitor $\mathrm{C} 1, \mathrm{C} 2 \quad[\mu \mathrm{f}] /[\mathrm{V}]$ & $2200 / 63,100 / 63$ \\
\hline Smoothing Inductor L $[\mathrm{mH}]$ & 27 \\
\hline Capacitance of snubber circuit & $1000 \mu \mathrm{F} / 63 \mathrm{~V}$ \\
\hline Resistance of snubber circuit & $330 \mathrm{ohm} / 20 \mathrm{~W}$ \\
\hline Power MOSFET & $\mathrm{IRF} 840$ \\
\hline Power diode & $\mathrm{IN4007}$ \\
\hline
\end{tabular}

Table 8 Circuit parameters for modified forward converter

\begin{tabular}{|lc|c|}
\hline Parameters & Unit & $\begin{array}{c}\text { Values and } \\
\text { Items }\end{array}$ \\
\hline Input voltage & {$[\mathrm{V}]$} & 100 \\
\hline Output voltage Vo & {$[\mathrm{V}]$} & 42 \\
\hline Switching frequency & {$[\mathrm{kHz}]$} & 20 \\
\hline Smooth Capacitor $\mathrm{C} 1, \mathrm{C} 2$ & {$[\mu \mathrm{f}] /[\mathrm{V}]$} & $2200 / 63,100 / 63$ \\
\hline Smoothing Inductor $\mathrm{L}$ & {$[\mathrm{mH}]$} & 27 \\
\hline Capacitance of snubber circuit $[\mathrm{nF}]$ & 100 \\
\hline Inductance of snubber circuit $[\mu \mathrm{H}]$ & 10 \\
\hline \multicolumn{2}{|l|}{ Power MOSFET } & IRF 840 \\
\hline Power diode & IN4007 \\
\hline
\end{tabular}


Circuit parameter for conventional boost forward converter is shown in Table 7. The circuit parameter for the modified forward converter with auxiliary resonant snubber is shown in Table 8 . The conventional boost forward converter is shown in Fig. 5a). DC output voltage is shown in Fig. 5b). The modified forward converter using auxiliary switch and the DC output voltage are shown in Fig. 5c) and 5d). The modified forward converter with auxiliary resonant snubber is implemented with PIC 16F84 microcontroller, which is compare with the simulation results.

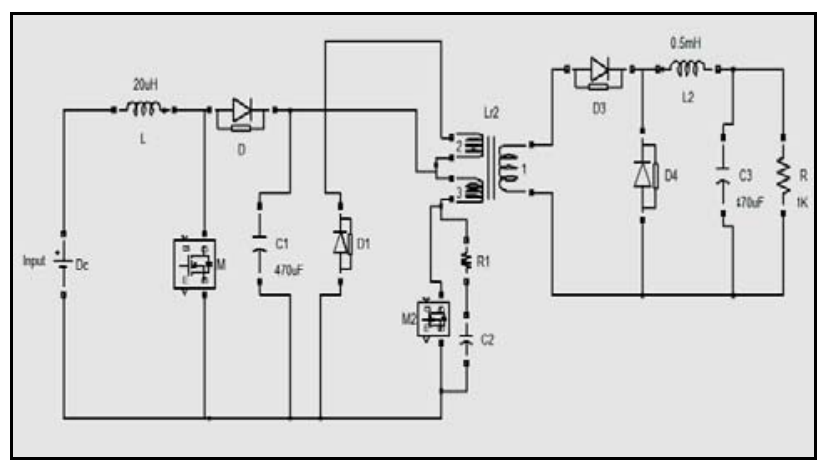

Fig. 5a) Conventional boost forward converter

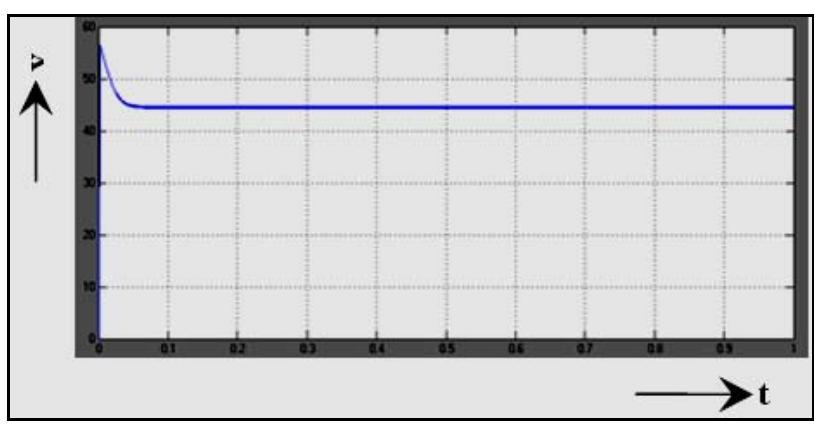

Fig. 5b) DC output voltage

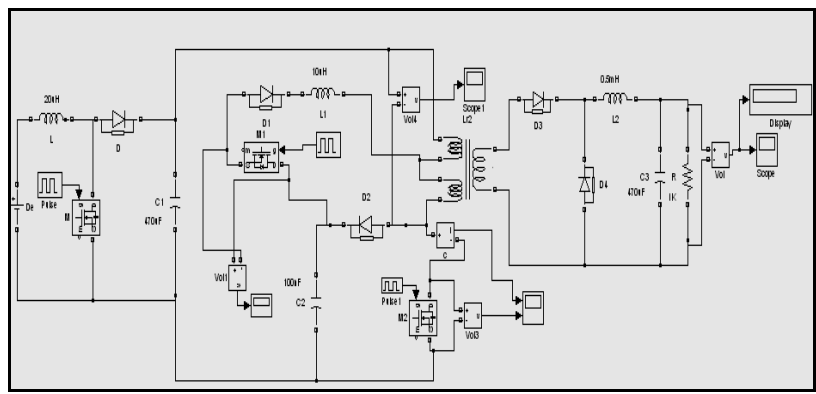

Fig. 5c) Modified forward converter using auxiliary switch

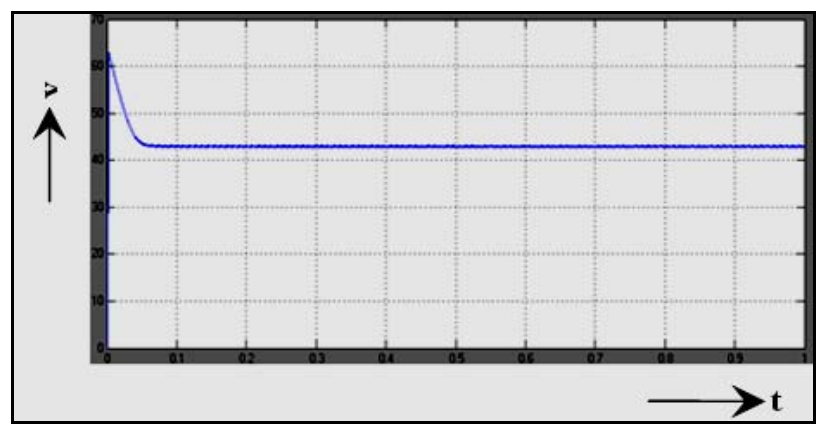

Fig. 5d) DC output voltage

\section{EXPERIMENTAL RESULTS}

Experimental set-up of a modified forward converter is developed using PIC microcontroller. The PIC microcontroller PIC16F84A is used to generate the driving pulses for the main switch and the snubber switch with (NPC-ARS), to turn on and off to process and the experimental results are obtained. The modified low noise SMPS System with forward type soft switching DC-DC Converter with a neutral point inductor connected auxiliary resonant snubber circuit is designed and the schematic module is shown in Fig. 6a). The hardware module is shown in Fig. 6b). The inductor voltage and the capacitor voltage in the NPC-AR snubber circuit are shown in Fig. 6c) and Fig. 6d). The DC output voltage is shown in the oscillogram of Fig. 6e). The experimental results are obtained for constant load.

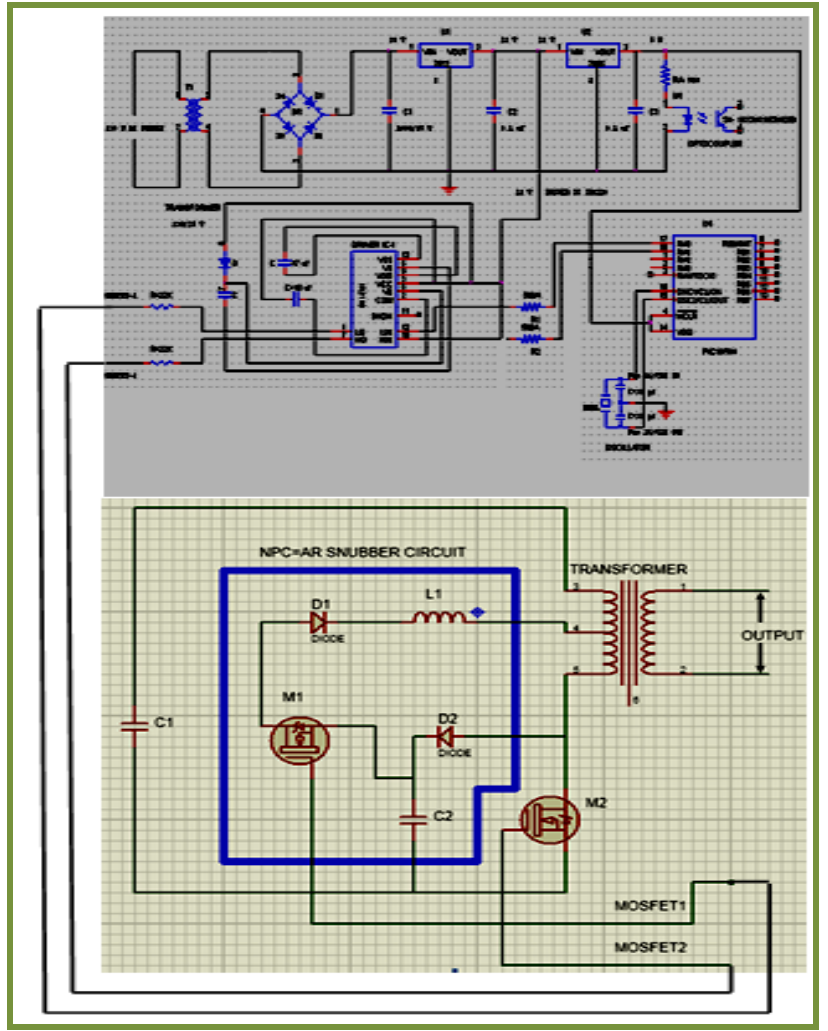

Fig. 6a) Schematic arrangement of hardware module

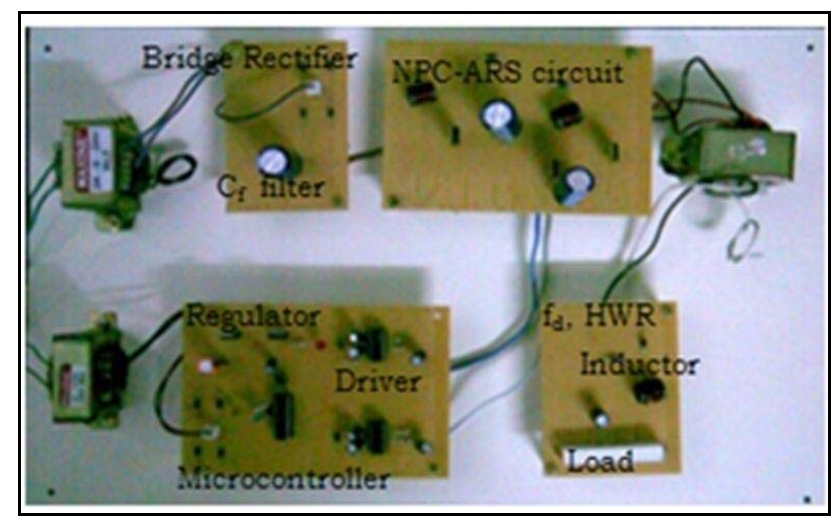

Fig. 6b) Hardware module 


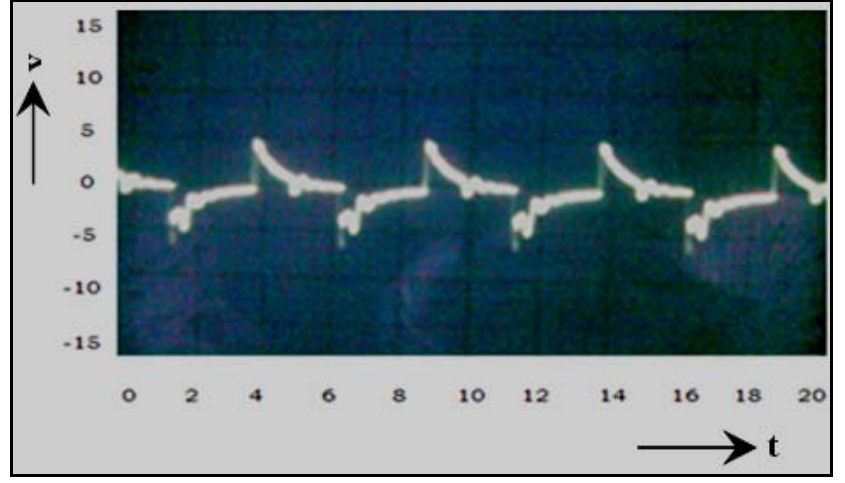

Fig. 6c) Inductor voltage in the snubber circuit

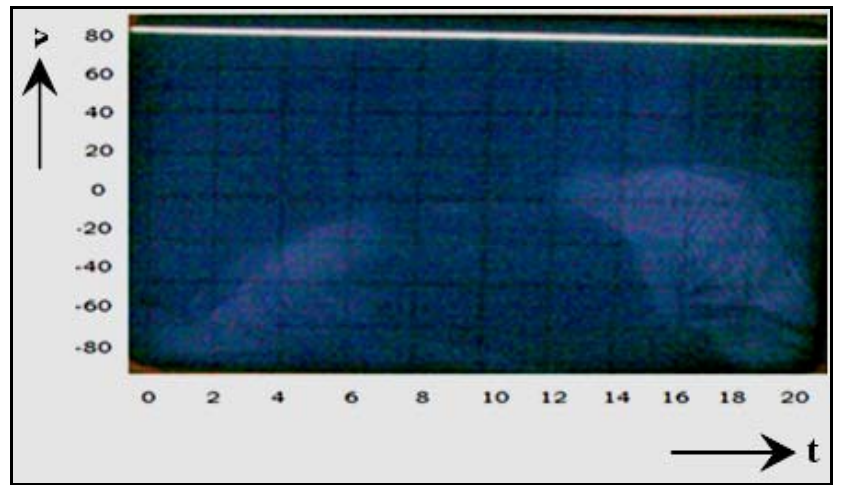

Fig. 6d) Capacitor voltage in the snubber circuit

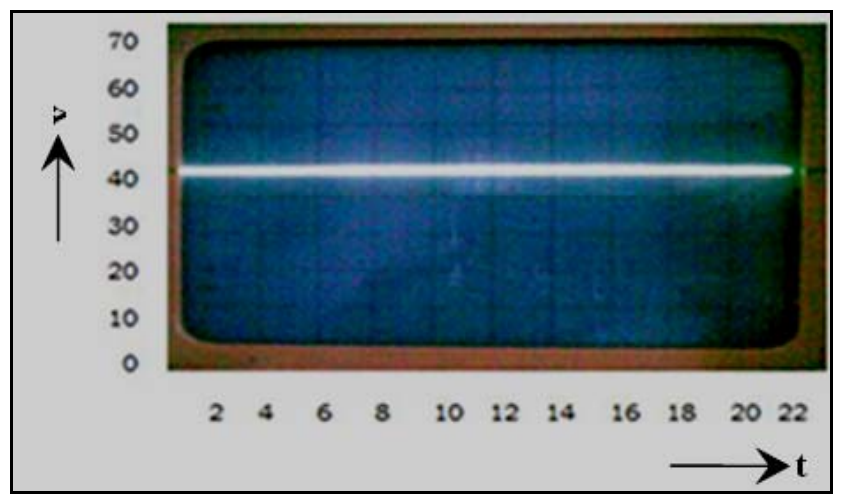

Fig. 6e) DC Output voltage

The comparison from the modified converter Fig. 5d) with the Fig. 6d), the simulation results and experimental results are closely agreed.

\section{CONCLUSION}

Forward converter with RCD snubber, double forward converter and the modified SMPS system are simulated using the blocks of simulink. Open loop controlled and the closed loop controlled forward converters are simulated and the range of steady state, transient response and the steady state error are obtained. From the comparison of the output voltage, the modified forward converter is found to have reduced the steady state error is reduced in the output and it is free from noise. From the results, it is observed that the modified forward converter is suitable for the SMPS System. The simulation results and the experimental results of the modified system are compared. The modified converter has reduced the noise in the output. From the results, it is observed that the experimental results closely agree with the simulation results.

\section{REFERENCES}

[1] LÓPEZ del MORAL, D. - BARRADO, A. - SANZ, M. - LÁZARO, A. - FERNANDEZ, C. - ZUMEL, P.: High efficiency DC-DC autotransformer forward-fly-back converter for DMPPT architectures in solar plants, IEEE Conference Publications, 2015, pp. 431-436.

[2] AHMED, M. M. - USHA, A. - SHIRSI, I. SINGH, B.K. - PRAKASH, B.: A Feed forward Voltage Mode Controlled ZVS based Phase shifted $300 \mathrm{~W}$ full bridge DC-DC converter for military application, Control Engineering (ICPACE), IEEE Conference Publications, 2015, pp. 238-243.

[3] IBANEZ, F. M. - ECHEVERRIA, J. M. ASTIGARRAGA, D. - FONTAN, L.: Soft-switching forward DC-DC converter using a continuous current mode for electric vehicle applications Power Electronics, IET, Vol. 8, Issue 10, 2015, pp. 19781986.

[4] KHALILIAN, M. - ADIB, E.: Soft-single-switched dual forward-fly-back PWM DC-DC converter with non-dissipative LC circuit Electrical Engineering (ICEE), 23rd Iranian Conference, IEEE Conference Publications, 2015, pp. 1562-1567.

[5] FEI LU - HUA ZHANG - HOFMANN, H. - MI, Ch.: A Double-Sided LCLC-Compensated Capacitive Power Transfer System for Electric Vehicle Charging, IEEE Transactions on Power Electronics, Vol. 30, Issue 11, 2015, pp. 6011-6014.

[6] YI-PING HSIEH - JIANN-FUH CHENN - LUNGSHENG YANG - WEI-SHIH LIU: High conversion ratio bidirectional DC-DC converter with coupled inductor, IEEE Transactions on Industrial Electr., Vol. 61, No. 1, 2014.

[7] VIJAYAKUMAR, P. - RAMAREDDY, S.: Closed Loop Controlled Low Noise SMPS System Using Forward Converter, International Journal of Computer and Electrical Engineering, Vol. 3, No. 1, 2011, pp. 74-78.

[8] VIJAYAKUMAR, P. - RAMAREDDY, S.: Simulation Results of Double Forward Converter, International Journal the annals of dunarea dejos, University of Galati, Fascicle III, Vol. 32, No. 2, 2009, pp. 51-57.

[9] VIJAYAKUMAR, P. - RAMAREDDY, S.: Simulation Results of Forward Converter with Improved Efficiency for SMPS System, European Journal of Scientific Research, Vol. 114, No. 2, 2013, pp. 295-303. 
[10] ARSALAN ANSARI, PUYANG CHENG - HEEJUN KIM: A $3 \mathrm{~kW}$ Bidirectional DC-DC Converter for Electric Vehicles, Journal of Electrical Engineering Technology, 11(4), 2016, pp. 709-718.

Received January 2, 2017, accepted May 23, 2017

\section{BIOGRAPHIES}

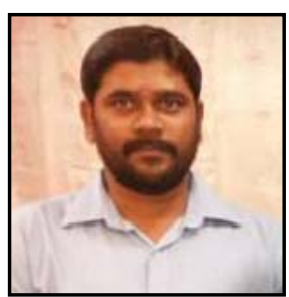

A. Palamalai Vijayakumar received his Ph.D from Jawaharlal Nehru Technological University (JNTUH), Telangana, Hyderabad, India in 2016, M.Tech degree in Power Electronics and Drives from Bharath Institute of Higher Education and Research, Bharath University, Chennai, India in 2005, B.E degree in Electronics and Communication Engineering from V.R.S College of Engineering and technology, Madras University, Chennai, India in 2002 and Diploma in Electrical and Electronics Engineering from A.S.A
Polytechnic, Tenkasi in 1995. He has 10 years of teaching experience and 8 years of Industrial experience and he is a member of IEEE. His research area is on converter system with fuzzy logic, artificial neural networks, VLSI Design and embedded microcontroller.

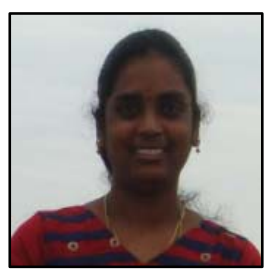

Ramakrishnan Devi received her B.Tech degree in Information Technology from V.R.S College of Engineering and Technology, Anna University, Chennai, India in 2005 and M.E degree in Computer Science and Engineering from Sri Krishna Engineering College, Anna University, Chennai, India in 2007. Currently she is working as Assistant Professor in Panimalar Engineering College, Chennai, India. She has 8 years of teaching experience. Her interested area in the field of embedded system, Low and high power electronics, System software, Compiler design, Oops, and Data structures. Her research area is on embedded system in low power electronics with real-time applications, such as fuzzy logic, artificial neural networks, VLSI Design and embedded microcontroller. 